\title{
Analisis Pendapatan Usahatani Keladi di Kepenghuluan Darussalam Kecamatan Sinaboi Kabupaten Rokan Hilir
}

\author{
Eliza*, Ermi Tety, Yuliansyah Putra \\ Jurusan Agribisnis, Fakultas Pertanian, Universitas Riau \\ * eliza_unri@yahoo.com
}

\begin{abstract}
Abstrak. Penelitian ini bertujuan untuk menganalisis biaya produksi, pendapatan, dan kelayakan usahatani keladi di Kepenghuluan Darussalam Kecamatan Sinaboi Kabupaten Rokan Hilir. Penelitian menggunakan metode survei. Teknik pengambilan sampel secara purposive sampling yaitu petani keladi yang memiliki lahan $\geq 1$ Ha diambil sampel sebanyak 30 orang. Jenis data dan sumber data adalah data primer dan sekunder. Model analisis yang digunakan adalah analisis biaya produksi, pendapatan, keuntungan dengan rumus $\pi=$ TR-TC dan kelayakan usahatani secara ekonomi dengan formula RCR $=$ TR/TC. Hasil penelitian menunjukkan bahwa rata-rata biaya produksi usahatani keladi sebesar Rp 9.989.725,34/Ha/MT) terdiri dari biaya variabel sebesar Rp 7.456.316,00/Ha/MT dan biaya tetap sebesar Rp 2.533.409,34/Ha/MT dengan pendapatan rata-rata sebesar 22.566.848,00/Ha/MT dan rata-rata keuntungan sebesar Rp 12.577.122,66/Ha/MT. Analisis R/C ratio usahatani keladi di Kepenghuluan Darussalam Kecamatan Sinaboi Kabupaten Rokan Hilir sebesar 2,26 berarti usahatani keladi yang dilakukan secara ekonomi layak untuk diusahakan. .
\end{abstract}

Kata Kunci: usahatani keladi, biaya produksi, pendapatan, kelayakan usaha

\section{PENDAHULUAN}

Sektor pertanian memiliki peranan penting dalam pertumbuhan dan ketahanan ekonomi nasional. Pembangunan pertanian dihadapkan kepada kondisi lingkungan yang strategis yang terus berkembang secara dinamis dan menjurus kepada liberalisasi perdagangan internasional, untuk memanfaatkan peluang yang ada, maka pembangunan pertanian harus lebih difokuskan kepada komoditi-komoditi unggulan yang dapat bersaing di pasar domestik maupun pasar internasional. Kondisi ini menjadi dasar yang kuat bagi pemerintah untuk mempercepat laju pertumbuhan pertanian di Indonesia yang berwawasan agribisnis guna meningkatkan peranan ekonomi nasional. Agribisnis dapat diterapkan pada semua komoditi dalam usahatani dibidang pertanian yang salah satunya adalah komoditi keladi.

Kabupaten Rokan Hilir merupakan sebuah Kabupaten yang terletak di Provinsi Riau. Hampir 50\% perekonomian di Kabupaten Rokan Hilir bersumber dari sektor pertanian, sehingga pembangunan bidang ekonomi dititikberatkan pada sektor pertanian guna mendorong dan menopang sektor industri dan sektor perdagangan serta sektor-sektor lainnya. Pembangunan sektor pertanian diarahkan untuk meningkatkan produksi pangan, palawija, dan holtikultura.

Pada tahun 2015 luas lahan di Kabupaten Rokan Hilir tercatat 888.142 ha, lahan yang digunakan untuk perkebunan 381.298 ha $(43,00 \%)$, tegal/kebun/ladang/huma 64.427 ha $(7,00 \%)$, pekarangan 353.183 ha $(40,00 \%)$, tanaman kayu-kayuan 13.566 ha $(2,00 \%)$, lahan yang sementara tidak diusahakan 18.496 ha (2,00\%), sawah 29.236 ha (5,00\%), padang rumput 128 ha (0,02\%), dan sisanya seluas 27.825 ha $(3,00 \%)$ digunakan untuk lain-lain (BPS Kabupaten Rokan Hilir, 2016).

Luas lahan keladi di Kabupaten Rokan Hilir pada tahun 2015 tercatat seluas 238 hektar. Kecamatan Sinaboi merupakan sentra pengembangan keladi di Kabupaten Rokan Hilir dengan luas lahan keladi sebesar 217 hektar, produksi 4.125 ton, dengan produktivitas mencapai 19 ton/hektar.

Kepenghuluan/Desa Darussalam merupakan salah satu sentra pengembangan keladi di Kecamatan Sinaboi, dimana pada tahun 2015 tercatat produksi keladi sebesar 2.325 ton dengan produktivitas mencapai 25 ton/hektar (UPTD Pertanian Kecamatan Sinaboi, 2015).

To cite this article: Eliza., E. Tety., dan Y. Putra. 2019. Analisis Pendapatan Usahatani Keladi di Kepenghuluan Darussalam Kecamatan Sinaboi Kabupaten Rokan Hilir. Unri Conference Series: Agriculture and Food Security 1: 26-33.

https://doi.org/10.31258/unricsagr.1a4 
Keladi adalah sekelompok tumbuhan dari genus Caladium (suku talas-talasan, Araceae). Keladi merupakan tanaman umbi-umbian yang memiliki banyak manfaat. Selain untuk menurunkan kadar gula darah, keladi juga bermanfaat untuk kesehatan percernaan, mencegah beberapa jenis kanker, melindungi kulit, meningkatkan kesehatan mata, meningkatkan sirkulasi darah dan dipercaya bisa mencegah penyakit jantung.

Budidaya keladi terbilang cukup mudah untuk dilakukan, namun pengembangan usahatani keladi di Kepenghuluan Darussalam masih mengalami kesulitan untuk meningkatkan hasil produksi, hal tersebut disebabkan adanya berbagai keterbatasan yang dialami petani baik dari aspek budidaya maupun aspek pengolahan. Keterbatasan pada aspek budidaya adalah budidaya yang belum menerapkan manajemen budidaya yang baik yaitu penggunaan faktor produksi pupuk belum sesuai dengan dosis yang dibutuhkan tanaman keladi untuk bisa berproduksi tinggi. Lahan yang digunakan petani untuk budidaya tanaman keladi adalah lahan rawa.

Kegiatan usahatani keladi di Kepenghuluan Darussalam ditujukan untuk meningkatkan pendapatan masyarakat, ketersediaan bahan pangan secara internal dan ekternal uyang mampu memenuhi permintaan keladi. Oleh karena itu perlu dikaji tentang usahatani (on farm). Adapun tujuan penelitian adalah mengetahui Tujuan penelitian ini adalah (1) menganalisis biaya produksi usahatani keladi, (2) menganalisis pendapatan dari usahatani keladi, dan (3) menganalisis kelayakan usahatani keladi di Kepenghuluan Darussalam Kecamatan Sinaboi Kabupaten Rokan Hilir.

\section{KAJIAN PUSTAKA}

Tanaman keladi (Colocasia esculenta (L.) Schott) merupakan tanaman tahunan (perennial) yang bersifat sukulen (herbaceous) yaitu banyak mengandung air. Keladi memiliki andil yang besar dalam memenuhi kebutuhan karbohidrat dan perbaikan gizi masyarakat, serta dapat dijadikan sebagai bahan makanan yang bersubstitusi dengan beras, adapun kandungan gizi yang tinggi baik keladi mentah dan keladi rebus adalah nilai energi masing-masing $120 \mathrm{kal}$ dan $108 \mathrm{kal}$.

Jenis keladi yang umum dibudidayakan seperti keladi Bogor, Keladi Belitung, Keladi Padang (C. gigantean Hook. F.)/ Tanaman keladi dapat tumbuh pada ketinggian optimal antara 250-1.100 meter dari permukaan laut. Keladi juga dapat ditanam diberbagai kondisi curah hujan, namun pertumbuhan tanaman akan lebih baik lagi apabila ditanam pada tempat-tempat yang hampir selalu dalam keadaan lembab dengan curah hujan rata-rata $1.000 \mathrm{~mm}$ per tahun. Suhu optimal untuk pertumbuhan tanaman talas adalah antara 21 hingga 270C Direktorat Budidaya Aneka Kacang dan Umbi (Dirkabi).

Pengelolaan usahatani adalah kemampuan petani menentukan, mengkoordinasikan faktor-faktor produksi yang dikuasai sebaik-baiknya dan mampu memberikan produksi pertanian sebagaimana yang diharapkan, faktor produksi terdiri dari lahan, modal (bibit, pupuk, pestisida), tenaga kerja dan entrepreneur (Soekartawi, 2009). Analisis usahatani adalah suatu kegiatan untuk melakukan perhitungan ekonomis terhadap usahatani yang dilakukan yang akan memberikan gambaran bahwa apakah usaha yang dilakukan mengguntungkan atau sebaliknya.

Hasil penelitian Silalahi (2009) tentang analisis pendapatan usahatani dan pemasaran talas di Kelurahan Situgede, Kecamatan Bogor Barat, Kota Bogor menunjukkan setiap hektar lahan pertanian talas mampu menghasilkan rata-rata 18.000 umbi, dengan harga rata-rata Rp 1.586 per umbi untuk petani lahan disewa, Rp 1.635 per umbi untuk petani lahan sendiri dan Rp 1.621 per umbi untuk petani lahan keseluruhan. Ratarata pendapatan atas biaya total usahatani lahan disewa dan lahan milik sendiri masing-masing sebesar Rp 11.524.717,92, dan Rp 11.326.827,54, sedangkan pendapatan usahatani lahan keseluruhan adalah $\mathrm{Rp}$ 11.476.748,81. Nilai R/C rasio atas biaya total pada usahatani lahan disewa, lahan milik sendiri dan lahan keseluruhan masing-masing adalah 1,61; 1,56 dan 1,58. Hal ini menunjukkan bahwa usahatani talas terhadap lahan sendiri maupun lahan sewa sama-sama menguntungkan.

Arifin (2015) melakukan penelitian yang berjudul pengembangan tanaman talas bentul komoditas unggulan pada lahan rakyat di Kecamatan Pengantenan Kabupaten Pamekasan menyimpulkan bahwa Nilai $\mathrm{R} / \mathrm{C}$ Ratio usahatani talas /usahatani/musim sebesar 2,28. Ini berarti setiap $\mathrm{Rp}$ 1,00 modal yang diinvestasikan untuk usatani talas akan memberikan penerimaan sebesar 2,28 sehingga usahatani talas layak diusahakan bagi petani di Kec.Pegantenan. Oleh karena itu keputusan yang diambil oleh petani tepat dan usahatani talas tetap diusahakan. 


\section{METODE}

Penelitian ini dilaksanakan di Kepenghuluan Darussalam Kecamatan Sinaboi Kabupaten Rokan Hilir Provinsi Riau, dengan pertimbangan daerah tersebut sentra produksi keladi di Kecamatan Sinaboi. Penelitian dilaksanakan selama 4 bulan terhitung mulai bulan Juli 2017 sampai dengan Oktober 2017.

Sumber data dalam penelitian ini adalah data primer dan sekunder. Data primer diperoleh melalui wawancara langsung dengan petani keladi dengan menggunakan daftar pertanyaan (kuesioner). Data sekunder diperoleh dari instansi terkait dengan penelitian ini.

Penelitian menggunakan metode survey, pengambilan sampel dilakukan dengan metode metode purposive sampling adalah teknik menentukan sampel penelitian dengan beberapa pertimbangan tertentu yang bertujuan agar data yang diperoleh nantinya bisa lebih representatif (Sugiyono, 2010). Populasi petani keladi di Kepenghuluan Darussalam yang memiliki luas lahan besar sama dengan $1 \mathrm{Ha}$, diambil sebagai sampel sebanyak 30 petani keladi.

Untuk menjawab tujuan penelitian biaya produksi, pendapatan dan kelayakan usahatani keladi dianalisis dengan menggunakan rumus menurut Soekartawi (2009) yaitu:

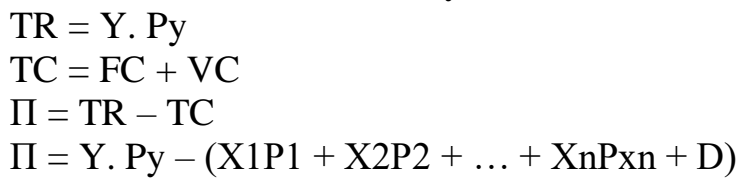

dimana:

TR $\quad=$ Pendapatan usahatani keladi $(\mathrm{Rp} / \mathrm{Ha} / \mathrm{MT})$

TC = Biaya produksi usahatani keladi $(\mathrm{Rp} / \mathrm{Ha} / \mathrm{MT})$

FC $\quad=$ Biaya tetap usahatani keladi $(\mathrm{Rp} / \mathrm{Ha} / \mathrm{MT})$

$\mathrm{VC}=$ Biaya variabel usahatani keladi $(\mathrm{Rp} / \mathrm{Ha} / \mathrm{MT})$

$\mathrm{Y} \quad=$ Jumlah produksi keladi $(\mathrm{Rp} / \mathrm{Ha} / \mathrm{MT})$

Py $\quad=$ Harga Produksi keladi $(\mathrm{Rp} / \mathrm{Ha} / \mathrm{MT})$

$\pi \quad=$ Keuntungan usahatani keladi $(\mathrm{Rp} / \mathrm{Ha} / \mathrm{MT})$

$\mathrm{Xi} \ldots . . \mathrm{Xn} \quad=$ Jumlah input $(\mathrm{i} \ldots \mathrm{n})$

PX1....PXN = Harga faktor produksi $(\mathrm{Rp} / \mathrm{Kg}, \mathrm{Rp} / \mathrm{HKP})$

$\mathrm{D} \quad=$ penyusutan alat-alat pertanian $(\mathrm{Rp} / \mathrm{Ha} / \mathrm{MT})$

Menghitung penyusutan peralatan dengan metode garis lurus (Staight Line Method) menurut Suratyah (2006) adalah:

$$
\mathrm{NP}=(\mathrm{NB}-\mathrm{NS}) / \mathrm{UE}
$$

dimana:

$\mathrm{NP}=$ Nilai penyusutan alat $(\mathrm{Rp} / \mathrm{Unit} / \mathrm{MT})$

$\mathrm{NB}=$ Nilai beli alat $(\mathrm{Rp} / \mathrm{Unit} / \mathrm{MT})$

NS = Nilai sisa $(20 \% \mathrm{x}$ nilai beli) $(\mathrm{Rp} / \mathrm{Unit} / \mathrm{MT})$

$\mathrm{UE}=$ Umur ekonomis (per tahun)

Menghitung efisiensi usahatani digunakan dengan analisis Return Cost ratio (R/C) dengan rumus sebagai berikut:

$$
\mathrm{RCR}=\mathrm{TR} / \mathrm{TC}
$$

dimana:

RCR $=$ Return Cost Ratio

$\mathrm{TR}=$ Total revenue/Total pendaparan keladi $(\mathrm{Rp} / \mathrm{Ha} / \mathrm{MT})$

$\mathrm{TC}=$ Total Cost/Total biaya produksi keladi (Rp/Ha/MT)

Kriteria keputusan:

$\mathrm{R} / \mathrm{C}>1$, usahatani keladi layak (efisien)

$\mathrm{R} / \mathrm{C}<1$, usahatani keladi tidak layak (tidak efisien)

$\mathrm{R} / \mathrm{C}=1$, usahatani keladi impas (balik modal). 


\section{HASIL DAN PEMBAHASAN}

\section{Keadaan Geografis Lokasi Penelitian}

Kepenghuluan Darussalam memiliki luas wilayahnya $\pm 380,00 \mathrm{Km} 2$ atau 38.000,800 ha, terdiri 2 dusun 2 rukun warga $(\mathrm{RW})$ dan 10 rumah tangga $(\mathrm{RT})$, jarak dari ke Ibukota Kecamatan adalah $\pm 3 \mathrm{Km}$, jarak ke Ibukota Kabupaten $\pm 30 \mathrm{Km}$, sedangkan jarak ke Ibukota Provinsi adalah $\pm 343 \mathrm{Km}$. Kepenghuluan Darussalam mempunyai jumlah penduduk 1.618 orang terdiri dari 855 orang laki-laki, dan 763 orang perempuan. Posisi geografis wilayah Kepenghuluan Darussalam berada pada ketinggian 6 mdpl dan sebagian besar merupakan daerah dataran rendah dengan ketinggian 0-30 meter diatas permukaan laut (mdpl), beriklim tropis dengan rata-rata curah hujan satu tahun $215,33 \mathrm{~mm}$, dan temperatur udara berkisar antara $26^{\circ} \mathrm{c}-32^{\circ} \mathrm{c}$. Potensi pertanian yang ada di Kecamatan Sinaboi dapat dilihat Tabel 1.

Tabel 1. Jenis Komoditas, Luas lahan, dan Produksi Pertanian tanaman Pangan dan Perkebunan di Kecamatan Sinaboi Tahun 2015

\begin{tabular}{lcc}
\hline \multicolumn{1}{c}{ Jenis Komoditas } & Luas Lahan $(\mathrm{Ha})$ & Produksi (Ton) \\
\hline Padi Sawah & $2.304,00$ & $8.225,28$ \\
Jagung & 7,00 & 15,68 \\
Kedelai & 7,00 & 7,98 \\
Keladi & 217,00 & $4.125,00$ \\
Kacang Hijau & 1,00 & 1,04 \\
Karet & 27,00 & 4,71 \\
Kelapa & 94,00 & 34,35 \\
Kelapa Sawit & $1.828,00$ & $2.108,50$ \\
Kakao & 11,00 & 4,08 \\
Jumlah & $4.496,00$ & $14.526,62$ \\
\hline
\end{tabular}

Sumber: BPS Kabupaten Rokan Hilir, 2015

Tabel 1. Menunjukkan potensi pertanian di Kecamatan Sinaboi Kabupaten Rohil sangat beragam, potensi sub sektor tanaman pangan total luas lahan 2.536,00 (56,41\%) yang mana komoditas keladi merupakan kelompok tanaman pangan kedua terbesar dikembangkan setelah padi. Sedangkan subsektor perkebunan mempunyai luas lahan 1.960 atau 43,59\% yang didominasi tanaman kelapa sawit.

\section{Identitas Petani Responden}

Identitas petani responden merupakan faktor fisik yang ada pada diri petani yang akan mempengaruhi keberhasilan suatu usaha, dalam hal ini meliputi tingkat umur, Pendidikan formal terakhir yang dilalui, jumlah tanggungan keluarga, lus lahan. Untuk lebih jelasnya dapat dilihat Tabel 2 sebagai berikut.

Tabel 2. Identitas Responden Petani Keladi di Kepenghuluan Darussalam

\begin{tabular}{clcc}
\hline \multicolumn{1}{c}{ No } & \multicolumn{1}{c}{ Jdentitas } & Persentase (\%) \\
\hline 1 & Umur (tahun) & 4 & \\
& $21-30$ & 11 & 13,34 \\
& $31-40$ & 10 & 36,66 \\
& $41-50$ & 2 & 33,34 \\
& $51-58$ & 3 & 6,66 \\
& $>58$ & & 10,00 \\
2 & Tingkat Pendidikan & 5 & 16,67 \\
& Tidak Tamat SD & 10 & 33,33 \\
& SD & 11 & 36,67 \\
& SLTP & 4 & 13,33 \\
& SLTA & & 33,33 \\
& Jumlah Tanggungan (orang) & 10 & 56,67 \\
& $1-2$ & 17 & 10,00 \\
& $3-4$ & 3 & 33,33 \\
& $5-6$ & & 66,67 \\
\hline
\end{tabular}




\begin{tabular}{clcc}
\hline No & \multicolumn{1}{c}{ Identitas } & Jumlah (orang) & Persentase $(\%)$ \\
\hline 5 & Luas lahan $(\mathrm{Ha})$ & & \\
& $1-1.5$ & 19 & 63,33 \\
& $1,5-2$ & 11 & 36,67 \\
\hline
\end{tabular}

Tabel 2. Hasil penelitian menunjukkan umur petani responden berkisar antara 21 - 64 tahun dengan rata rata berumur 42,73 tahun, responden terbanyak berumur $31-40$ tahun (36,67\%). Tingkat Pendidikan petani responden tertinggi adalah SLTA dan terbanyak tamatan SLTP yakni 11 orang $(36,67 \%)$. Jumlah tanggungan keluarga rata-rata 3 -4 orang yaitu 17 orang $(56,67 \%)$ Petani keladi yang memiliki luas lahan terbanyak adalah $1-1,5$ hektar, yaitu 19 orang (63,33\%), dan petani dengan luas lahan terkecil adalah 1,5 - 2 hektar, yaitu 11 orang $(36,67 \%)$ Pengalaman usahatani keladi terbanyak 20 orang $(66,67 \%)$ adalah $3-4$ tahun. Dilihat dari identitas responden petani keladi banyak yang masih muda muda, hal ini akan mempegaruhi aktifitas usahatni yang dilakukannya.

\section{Keragaan Usahatani Keladi}

\section{Bibit}

Bibit adalah input produksi dan sarana produksi yang paling pertama yang harus disediakan oleh petani sebelum melakukan proses usahatani atau produksi primer. Bibit keladi yang digunakan petani di Kepenghuluan Darussalam ialah jenis keladi ungu yang didapatkan berupa anakan kedua atau ketiga dari pertanaman sebelumnya. Tanaman keladi dari jenis tersebut dapat dipanen antara 6-8 bulan. Kriteria bibit yang diperoleh ialah bibit yang sehat, warna pangkal cukup cerah dan tidak terserang penyakit. Rata-rata penggunaan bibit keladi di lokasi penelitian adalah 24.620 bibit/Ha Jumlah bibit keladi yang dibutuhkan dalam satu hektar lahan ialah sekitar 20.000 - 30.000 bibit. Bibit yang digunakan oleh petani keladi di Kepenghuluan Darussalam telah sesuai dengan anjuran Jumlah bibit yang di tanam untuk satu hektar \pm 25.000 batang dengan menggunakan jarak tanam $30 \times 70 \mathrm{~cm}$.

\section{Pupuk}

Pemupukan pada tanaman keladi penting sebagai penyedia unsur hara yang kurang atau bahkan tak tersedia ditanah menjadi tersedia untuk mendukung pertumbuhan tanaman. Berdasarkan hasil penelitian, dosis pupuk yang digunakan petani keladi di Kepenghuluan Darussalam masih jauh dari ketentuan pemupukan tanaman keladi dimana dosis pupuk untuk tanaman keladi yang terbaik dalam meningkatkan hasil produksi tanaman keladi yaitu untuk pupuk urea ialah dilakukan sebanyak tiga kali, yakni 30 hari setelah tanam (HST), 90 HST, dan 150 HST masing-masing dosis yang dianjurkan ialah $35 \mathrm{Kg} / \mathrm{Ha}, 50 \mathrm{Kg} / \mathrm{Ha}$, dan $50 \mathrm{Kg} / \mathrm{Ha}$. Untuk penggunaan pupuk TSP rekomendasi yang dianjurkan oleh Direktorat Budidaya Aneka Kacang dan Umbi (Dirkabi) (2013) ialah dilakukan sebanyak satu kali, yaki 30 hari setelah tanam (HST). Dosis yang dianjurkan ialah $50 \mathrm{Kg} / \mathrm{Ha}$. Untuk penggunaan pupuk KCL dan NPK Dirkabi (2013) tidak menetapkan berapa standar khusus untuk menggunakan kedua pupuk tersebut. Dosis penggunaan disesuaikan dengan berapa standar yang ada atau berdasarkan kebutuhan petani keladi (Dirkabi, 2013).

Hasil penelitian menunjukan penggunaan pupuk pada usahatani keladi di Kepenghuluan Darussalam terdiri dari Urea sebanyak 15,21 Kg/Ha, TSP 35,14 Kg/Ha, KCL 34,06 kg/Ha dan NPK 15,63 Kg/Ha. Penggunaan pupuk masih jauh dari rekomendasi, Alasann petani terbatasnya memberikan pemupukan pada tanaaman keladi karna petani berpendapatan kondisi tanah yang masih gembur karna usahatani keladi ini baru dikembangkan tahun 2015, selain itu keterbatasan modal yang dimiliki petani untuk membeli pupuk, Hal ini untuk jangka Panjang tidak bisa dipertahankan.

\section{Pestisida}

Pestisida digunakan untuk mencegah dan memberantas hama atau penyakit penganggu tanaman keladi bila serangan hama dan penyakit tidak terkendalikan, yang bertujuan untuk mendapatkan hasil output tanaman keladi. Berdasarkan hasil wawancara dengan petani keladi di Kepenghuluan Darussalam mengenai sarana produksi obat-obat pertanian berupa pestisida, petani keladi tidak memiliki kendala dalam mendapatkan obat-obat pertanian. Toko pertanian yang ada di Kepenghuluan Darussalam telah menyediakan obat-obat pertanian berupa regent yang dibutuhkan petani dalam berusahatani keladi, Jumlah pemakaian regent ratarata 2 Liter/ha/MT.

\section{Tenaga Kerja}


Tenaga kerja merupakan faktor penting dalam proses produksi. Sumber tenaga kerja yang digunakan pada usahatani keladi berasal dari dalam keluarga (TKDK) dan luar keluarga (TKLK), yang terdiri dari tenaga kerja pria dan wanita. Rata-rata penggunaan tenaga kerja dan biaya upah per Ha dapat dilihat pada Tabel 3.

Tabel 3. Rata-Rata Penggunaan Tenaga Kerja Usahatani Keladi Di Kepenghuluan Darussalam

\begin{tabular}{clcc}
\hline No & \multicolumn{1}{c}{ Kegiatan } & Tenaga Kerja $(\mathrm{HOK} / \mathrm{Ha} / \mathrm{MT})$ & Persentase \\
\hline 1 & Pengolahan Tanah & 13.29 & 31,26 \\
2 & Penanaman & 11,25 & 26,46 \\
3 & Pemupukan & 3,26 & 7,76 \\
4 & Penyiangan & 4,06 & 9,54 \\
5 & Pengendalian Hama & 1,25 & 2,94 \\
6 & Panen & 9,40 & 22,12 \\
\hline \multicolumn{2}{r}{ Jumlah } & 42,51 & 100,00 \\
\hline
\end{tabular}

Berdasarkan Tabel 3. Rata-rata penggunaan tenaga kerja pada usahatani keladi terbesar pertama adalah pengolahan tanah sebesar 13,29 HOK/Ha/MT (31,26 \%) kemudian terbesar kedua Penggunaan tenaga kerja penanaman 11,25 HOK/Ha?MT (26,46\%) dan terbesar ketiga pemanenan 9,40 HOK/Ha/MT $(22,12 \%)$. Rata-rata penggunaan tenaga kerja usahatani keladi sebesar 42,51 HOK/Ha/MT yang bersumber dari tenaga kerja dalam keluarga (TKDK) sebesar 73,23 \% dan TKLK sebesar 26,77\%. Hal ini menunjukkan penggunaan tenaga kerja yang bersumber dar dalam keluarga lebih besar dari tenaga kerja luar keluarga.

\section{Peralatan Usahatani}

Peralatan usahatani adalah alat-alat yang digunakan petani keladi dalam menunjang operasional teknis budidaya keladi. Peralatan yang digunakan petani dalam usahatani keladi tidak berbeda dengan peralatan yang digunakan untuk bertani bagi komoditi lainnya, seperti parang, sabit, cangkul, Handsprayer, Sebagian besar petani tidak membeli peralatan setiap musim tanamnya karena peralatan dapat digunakan beberapa kali musim tanam. Peralatan yang digunakan akan mengurangi nilai dari alat tersebut yang disebut penyusutan, pada Tabel 4 dapat dilihat nilai penyusutan alat pertanian.

Tabel 4. Rata-Rata Penyusutan Peralatan Usahatani Keladi di Kepenghuluan Darussalam

\begin{tabular}{|c|c|c|}
\hline No & Jenis Peralatan & Biaya (Rp/Ha/MT) \\
\hline 1 & Parang & $13.865,17$ \\
\hline 2 & Sabit & $6.918,01$ \\
\hline 3 & Cangkul & $9.752,34$ \\
\hline 4 & Handspayer & $49.967,15$ \\
\hline & Jumlah & $80.502,67$ \\
\hline
\end{tabular}

\section{Biaya Produksi, Produksi, Pendapatan dan Kelayakan Usahatani Keladi}

Besarnya input yang akan digunakan dalam suatu proses produksi akan mempengaruhi produksi yang akan diperoleh serta biaya yang dikeluarkan untuk membeli input produksi tersebut. Besar kecil produki yang dihasilkan dikalikan dengan harga produksi akan mementukan pendapatan yang diperoleh petani dari usahatani keladi. Adapun produksi, biaya produksi, yang akan dikeluarkan dalam usahatani keladi serta pendapatan yang diperoleh serta kelayakan usahatani keladi dapat dilihat Tabel 5.

Tabel 5. Rata-Rata Biaya Produksi, Pendapatan dan Kelayakan Usahatani Keladi di Kepenghuluan Darussalam

\begin{tabular}{rrrr}
\hline \multicolumn{1}{c}{ No } & \multicolumn{1}{c}{ Uraian } & Biaya (Rp/Ha/MT) & Persentase \\
\hline A & Biaya Produksi & $9.989 .725,34$ & \\
1 & Biaya variabel & $7.456 .315,42$ & 74,64 \\
& Bibit & $4.924 .005,53$ & 66,04 \\
& Pupuk & 924.939 .72 & 12,40 \\
& Pestisida & $130.650,00$ & 1,75 \\
& TKLK & 909.399 .87 & 7,60 \\
& Karung & $566.320,17$ & 12,20 \\
& Biaya Tetap & $2.533 .409,34$ & 26,36 \\
& TKDK & $2.452 .906,67$ & 96,82 \\
\hline
\end{tabular}




\begin{tabular}{llrc}
\hline & \multicolumn{1}{c}{ Uraian } & Biaya $(\mathrm{Rp} / \mathrm{Ha} / \mathrm{MT})$ & Persentase \\
\hline & Penyusutan & $80.502,67$ & 3.18 \\
$\mathrm{~B}$ & Produksi & $7.052,14$ & \\
$\mathrm{C}$ & Pendapatan & $22.566 .848,00$ & \\
$\mathrm{D}$ & Keuntungan & $12.577 .122,66$ & 2,26 \\
$\mathrm{E}$ & Efisiensi (RCR) & & 2,26 \\
\hline
\end{tabular}

Pada Tabel 5 jumlah keseluruhan biaya yang dikeluarkan oleh petani keladi di Kepenghuluan Darussalam adalah hasil penjumlahan antara biaya variable dan biaya tetap. Total biaya tersebut adalah biaya produksi usahatani keladi ataupun total cost (TC). Hasil penelitian biaya produksi usahatani keladi sebesar Rp 9.989.725,34,-/Ha/MT, yang terdiri dari biaya variable sebesar Rp.7.456.315,42 /Ha/MT. Biaya variable terbesar adalah untuk pembelian bibit sebesar $66,04 \%$, sedangkan 34,06 \% digunakan untuk pembelian sarana produksi lainnya. Biaya tetap terbesar adalah untuk biaya tenaga kerja dalam keluarga yaitu 96,82\%.

Pada Tabel 5. Rata-rata produksi usahatani keladi yang dihasilkan sebesar $7.052 \mathrm{~kg}$ per musin tanam dengan harga per kg adalah Rp 3.200. Pendapatan usahatani adalah semua penerimaan yang diterima oleh petani keladi tersebut per musim tanam. Pendapatan usahatani keladi terbagi menjadi dua yakni, pendapatan kotor dan pendapatan bersih atau keuntung . Pendapatan kotor adalah semua penerimaan atau produsi dikali dengan harga jual. Pendapatan bersih adalah seluruh pendapatan kotor yang diperoleh oleh petani yang telah dikurangi biaya tetap dan biaya tidak tetap. Pada Tabel 5 pendapatan yang diterima petani keladi adalah sebesar Rp. 22.566.848,00 per musim tanam, sedangkan keuntungan diperoleh per hektar per musim tanam sebesar Rp 12.577.122,66,-.

Kelayakan usahatani keladi dihitung dengan pedekatan analisis Return Cost Ratio (RCR) yaitu perbandingan (ratio atau nisbah) antara penerimaan (revenue) dengan biaya (cost). Hasil penelitian diketahui nilai RCR yang diperoleh usahatani keladi di Kepenghuluan Darussalam per musim tanam adalah 2,26 artinya setiap satu rupiah setiap satu rupiah biaya yang dikeluarkan dalam usahatani kedelai memperoleh pendapatan sebesar Rp.2,26, dan memperoleh keuntungan sebesar Rp. 1,26, Dengan kata lain usahatani kedelai menguntungkan dan layak untuk dilanjutkan.

\section{KESIMPULAN}

Berdasarkan hasil penelitiann usahatani keladi di Kepenghuluan Darussalam Kecamatan Sinaboi Kabupaten Rokan Hilir dapat disimpulkan:

1. Penggunaan sarana produksi pada usahatani keladi meliputi bibit keladi berjenis keladi unggu sudah sesuai menurut yang dianjurka, penggunaan pupuk, pestisida masih rendah dibandingkan dengan rekomendasi yang dianjurkan, penggunaan tenaga kerja dalam kelurrga 72,23\% lebih banyak dari tenaga kerja luar keluarga 26,77\%.

2. Rata-rata biaya produksi keladi sebesar 9.989.725,34/Ha/MT yang meliputi biaya variable sebesar Rp. 7.456.315,42/Ha/MT. dan biaya tetap sebesar Rp 2.533.409,34/Ha/MT. Biaya vabiabel terbesar adalah biaya bibit, sedangkan biaya tetap terbesar adalah biaya tenaga kerja dalam keluarga. Produksi keladi $7.052,14, \mathrm{~kg} / \mathrm{Ha} / \mathrm{MT}$. Pendapatan usahatani keladi rata-rata sebesar 22.566.848,00/Ha/MT dan rata-rata keuntungan sebesar Rp 12.577.122,58/Ha/MT. Nilai R/C Ratio sebesar 2,26 berarti usahatani keladi efisien dan layak untuk diusahakan.

Diharapkan pada petani sebaiknya memberikan pupuk sesuai dengan dosis yang anjuran / direkomendasikan dalam kegiatan budidaya keladi, serta meningkatkan pengetahuan dan ketrampilan petani dalam pengelolaan usahatani keladi melalui pembinaan oleh instansi pemerintah dan swasta agar produksi keladi dapat meningkatkan dimasa yang akan dating, dan menciptakan diversifikasi produk berbahan baku keladi.

\section{DAFTAR PUSTAKA}

Arifin, Z. 2015. Pengembangan Tanaman Talas Bentul, Komoditas Unggulan Pada Lahan Rakyat Di Kecamatan Pegantenan kabupaten Pamekasan. Jurnal Agrovigor 8(2): 16-32.

BPS Kabupaten Rokan Hilir. 2016. Kabupaten Rokan Hilir Dalam Angka. Badan Pusat Statistik. Kabupaten Rokan Hilir.

Direktorat Budidaya Aneka Kacang dan Umbi (Dirkabi). 2013. Informasi Pengembangan Aneka Umbi. Direktorat Jendreal Tanaman Pangan. Kementerian Pertanian Republik Indonesia. 
Silalahi 2009. Analisis Pendapatan Usahatani dan Pemasaran Talas di Kelurahan Situgede Kecamatan Bogor Barat Kota Bogor. Skripsi Fakultas Ekonomi dan Manajemen. Institut Pertanian Bogor.

Soekartawi. 2009. Ilmu Usahatani dan Penelitian Pengembangan Petani Kecil. Jakarta: Universitas Indonesia Press. Suratyah. 2006. Ilmu Usahatani. Jakarta: Penebar Swadaya.

Sugiyono. 2010. Metode Penelitian Pendidikan Pendekatan Kuantitatif, Kualitatif dan R \& D. Bandung: Alfabeta. UPTD Pertanian Kecamatan Sinaboi. 2015. Kecamatan Sinaboi Dalam Angka. Kabupaten Rokan Hilir. 